\title{
"Softciências" - Um Consórcio para Promover o Uso das Tecnologias Informáticas do Ensino das Ciências
}

\section{J O ÃO CARLOS PAIVA, \\ Descrevemos o projecto \\ "Softciências", uma acção \\ comum das Sociedades \\ Portuguesas de Física, Química e Matemática que produziu e difundia software para o ensino. aprendizagem e divulgacão das ciências básicas de 1991 a 1999. Apresentamos em particular 0 CD-ROM "OMNICIENCIA 98", que compila praticamente todos os materiais do projecto. A ênfase é colocada nos conteúdos de Quimica. \\ Explicitamos as principais linhas de forca que orientaram o projecto e algumas perspectivas do frabalho futuro nessa área.}

\section{INTRODUÇÃO}

"Softciências" foi uma acção comum das Sociedades Portuguesas de Física, Química e Matemática para produção e difusão de software para o ensino, aprendizagem e divulgação das ciências básicas. Essa acção pluridisciplinar foi apoiada pelo $\mathrm{Mi}$ nistério da Educação e, nos últimos tempos, pelo Ministério da Ciência e Tecnologia. A Sociedade Portuguesa de Física foi a gestora da acção.

A acção comum, iniciada em 1991 e terminada em 1999, produziu cerca de duas dezenas de programas de Física, Química e Matemática, que foram, individualmente e à medida que iam sendo terminados, distribuídos na comunidade escolar portuguesa.

Em 1998 o "Softciências" produziu e ofereceu a todas as escolas portuguesas, públicas e privadas, com ensino a partir do $8 .^{\circ}$ ano de escolaridade, o CD-ROM "OMNICIÊNCIA 98" (ver Figura 1), que beneficiou de apoio específico do $\mathrm{Mi}$ nistério da Ciência e Tecnologia. Trata-se de uma recolha de todos os programas de computador que a acção desenvolveu até então, assim como de algumas páginas "World Wide Web" (WWW) da Internet relativas ao ensino das ciências, que assim se tornam acessíveis localmen-

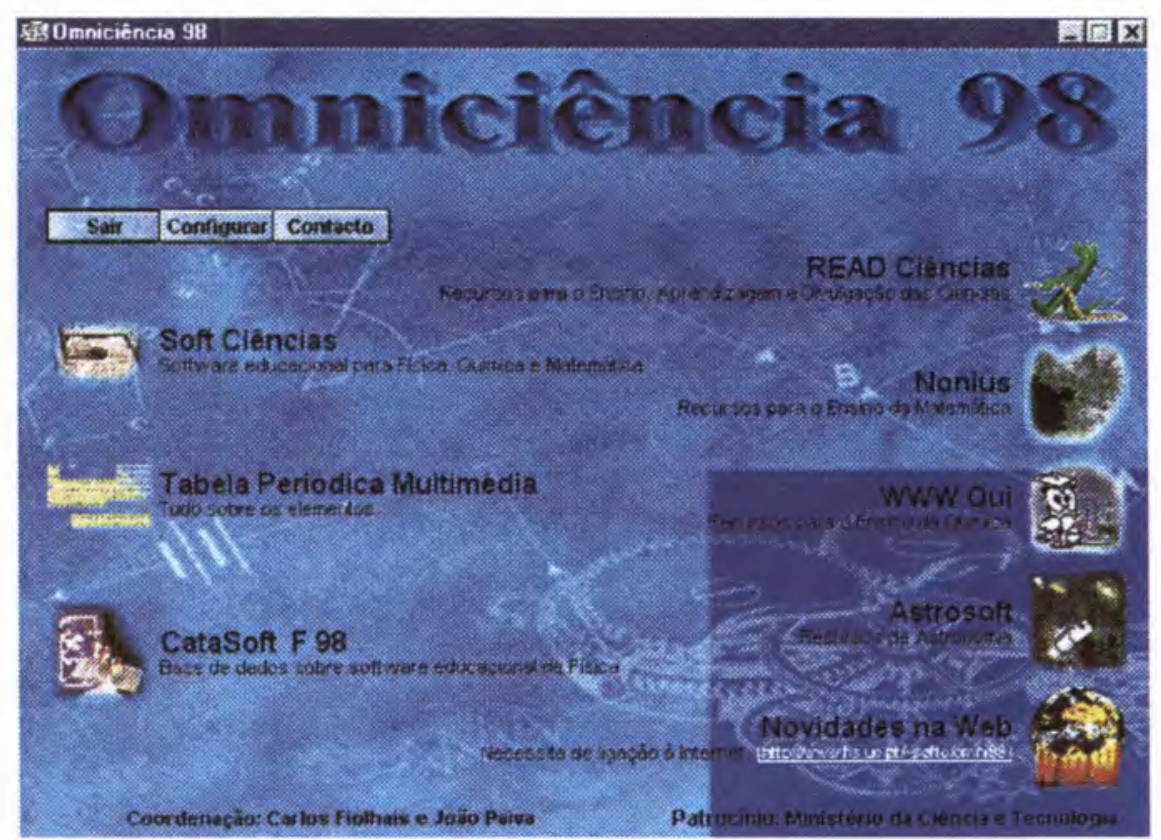

Fig. 1 - Écrã de entrada do CD-ROM "OMNICIÊNCIA 98".

te sem custos de comunicação. O "OMNICIÊNCIA 98" actualiza e substitui um disco semelhante intitulado "OMNICIÊNCIA 97", distribuído em 1997.

Uma vez que o disco "OMNICIÊNCIA 98" constitui um resumo actualizado da actividade desenvolvida pela acção comum, apresentamos os conteúdos do disco e indicamos algumas das suas utilidades. Os conteúdos do disco encontram-se à disposição da comunidade educativa no endereço http:// nautilus.fis.uc.pt / softc/omni98.

A acção comum "Softciências" teve uma vocação de serviço à comunidade dos professores e alunos de ciências (a Química e Física foram mais contempladas que a Matemática). Se, de início, a nossa preocupação foi o sistema de ensino português, tendo os conteúdos produzidos estado sempre que possível em sintonia com a última revisão curricular de ciências nos ensinos básico e secundário, o nosso serviço pôde também ser útil na generalidade dos países de língua portuguesa. Praticamente todos os nossos trabalhos en- contram-se disponíveis na Internet, podendo ser visionados e capturados livremente em qualquer lado do mundo. Por exemplo, os nossos programas tornaram-se acessíveis a professores e alunos no Brasil, permitindo continuar relações de cooperação que estabelecemos com instituições daquele país [1]. Atendendo à evolução da Internet e obedecendo aos objectivos essenciais do projecto (não só a criação de materiais mas também a sua difusão!) abandonámos progressivamente a distribuição de recursos em modo "off-line", em formato de disquete, privilegiando os canais telemáticos. Acontece que o CD-ROM é um formato compacto e económico, que pode complementar ou mesmo substituir com vantagem a informação "on-line" (por exemplo, quando as comunicações são lentas ou dispendiosas), embora a rede ofereça a vantagem da actualização permanente e o acesso regular de qualquer parte do mundo. No nosso caso, procurámos combinar os benefícios do "on-line" e do "offline" através da dupla versão em disco e na Internet. 


\section{CONTEUDO DO CD-ROM}

É o seguinte o conteúdo do CDROM "Omniciência 98":

1- 22 programas educativos (nove de Física, sete de Química, dois de Matemática e quatro de âmbito multidisciplinar).2- Tabela Periódica Multimédia.3- Catasoft F-98 (Catálogo de Software de Física).

4- READ Ciências (Recursos para o Ensino, Aprendizagem e Divulgação das Ciências).

5- Nonius (Recursos para o Ensino da Matemática).

6- WWW Qui (Recursos para o Ensino da Química).

7- Astrosoft (Recursos de Astronomia). Web

8- Novidades OMNICIÊNCIA na

O primeiro grupo (22 programas e Tabela Periódica Multimédia) é constituído por programas para o ensino das ciências. O segundo é constituído por diferentes páginas WWW de recursos para o ensino das ciências. Por último, as Novidades referem-se a uma ligação para actualizações na rede. Descrevemos de seguida e resumidamente o conteúdo de alguns items, com ênfase particular na área da Química.

\section{PROGRAMAS EDUCATIVOS}

\section{Le Chat}

O programa "Le Chat", subintitulado "Simulações em Equilíbrio Químico" e cujo nome é um jogo da palavra gato e do nome do químico francês Le Châtelier, consiste basicamente numa ilustração no computador, de uma forma gráfica atractiva, dos fenómenos do equilíbrio químico. Em particular, visualizam-se as alterações produzidas em sistemas químicos gasosos por alterações de concentrações de reagentes ou produtos, temperatura ou pressão, em conformidade com o Princípio de Le Châtelier. Os autores são João Paiva, Antero Abrunhosa e Victor Gil. Uma discussão

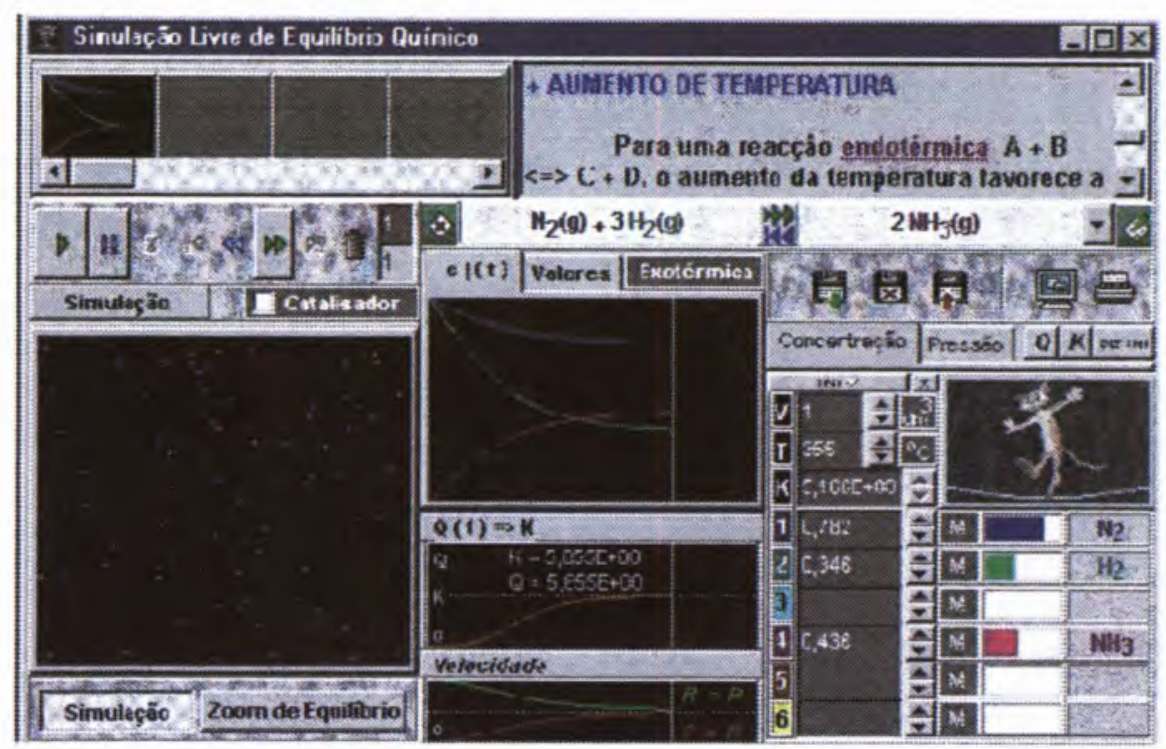

Fig. 2 - O programa Le Châtelier 2.0, para estudar o equilibrio químico.

mais pormenorizada do programa encontra-se na tese de mestrado do primeiro autor [2] efectuada sob a co-orientação do último. Na versão 2.0 de "Le Chat", cujos autores são João Paiva, Ilídio Martins, Victor Gil e António Ferrer Correia, incluíram-se bastantes modificações e acrescentos de modo a melhorar e completar o programa (figura 2). Esta nova versão do programa pode ser capturada livremente na Internet em http://nautilus.fis.uc.pt 1 Wwwqui, estando também a ser distribuída em disquete [3].

Uma versão inglesa deste programa foi aceite para publicação no "Journal of Chemical Education Software".

\section{Jogo das Coisas}

O "Jogo das Coisas" é um conjunto de jogos de "fazer pensar" que podem servir em todos os grupos disciplinares. Nasceu de uma experiência dos seus autores no domínio do ensino da Química ("Jogo das Substâncias Químicas"). A ideia, que consiste na "escolha secreta" pelo computador de uma substância de entre um dado conjunto e no convite ao utilizador para adivinhar a substância escolhida, a partir das suas propriedades e usando o menor número possível de perguntas, foi bem acolhida por professores e alunos. O "Jogo das Substâncias" pode, por exemplo, ser bastante animado e conduzir a uma aprendizagem divertida da química das substâncias. Os autores do programa são Victor Gil, João Paiva e Fausto Cação.

Está disponível no CD-ROM um "Jogo das Coisas Multimédia", cujos autores são João Paiva, Ilídio Martins e Victor Gil, e que constitui, como o próprio nome indica, uma extensão multimedia do programa anterior, com todas as vantagens que são inerentes ao multimédia [4].

\section{Millikan}

O programa "Millikan" (a que demos o nome alternativo de "Electrão", temendo que o nome do físico norte-americano Robert Millikan não fosse suficientemente conhecido nas nossas escolas) pretende simular no computador uma das experiências científicas mais importantes deste século: a experiência de Millikan 
Mo00 denonstrasaio Electrăo experiência de Millikan
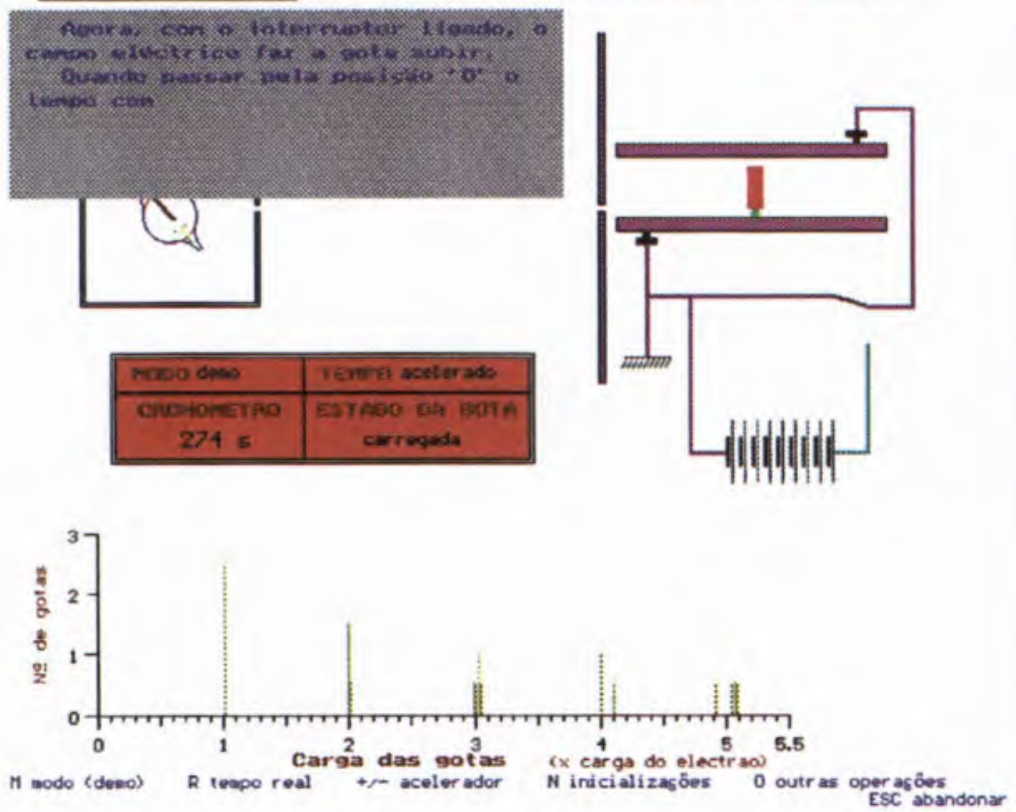

Fig. 3 - O programa Millikan, que simula a experiência de Millikan.

para medir a carga do electrão. Várias actividades escolares e para-escolares podem ser desenvolvidas em torno desta recriação (simular é, de certa forma, recriar e, se a simulação for bem feita, pode ser também recrear!) da experiência de Millikan, embora o estudo pormenorizado desta não seja objecto explícito dos actuais programas (figura 3). De facto, os únicos conhecimentos de Física que são necessários referem-se ao movimento de uma partícula com velocidade terminal, portanto sob a acção de forças cuja resultante é nula. Esta simulação pode ser feita de dois modos: automática e manualmente; no primeiro, basta correr a demonstração e, no segundo, o utente dispõe do controlo total de todas as variáveis. Como todas as simulações, não pretende de modo nenhum substituir a realização da experiência real mas sim elucidá-la. Para tornar a simulação mais realista incluímos erros nas medidas. Os autores do programa são Paulo César Simões, Paulo Saturnino e Carlos Fiolhais.

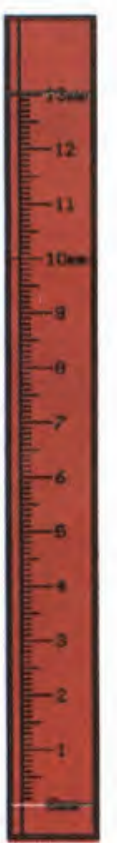

Zero

Esta é uma ferramenta informática destinada essencialmente a professores. O programa "Zero", actualmente na versão 3.0, concebe e aleatoriza testes de múltipla escolha, que podem estar associados a testes convencionais de resposta aberta. O programa permite posteriormente a correcção dos testes usando um "scanner". Permite igualmente a impressão nos testes preenchidos das avaliações e correcções respectivas. Tudo isto se faz sem grande dispêndio de tempo para o utilizador (daí o nome "zero"). Levando embora em conta as discussões sobre a problemática de testes de múltiplas escolha [5], pretendemos que o professor, ao utilizar este programa, verifique as vantagens óbvias das novas tecnologias na sua profissão, nomeadamente libertando o tempo dispendido na correcção de provas para outras actividades bem mais interessantes e profícuas. O "Zero", tal como todos os outros programas aqui descritos, pode ser

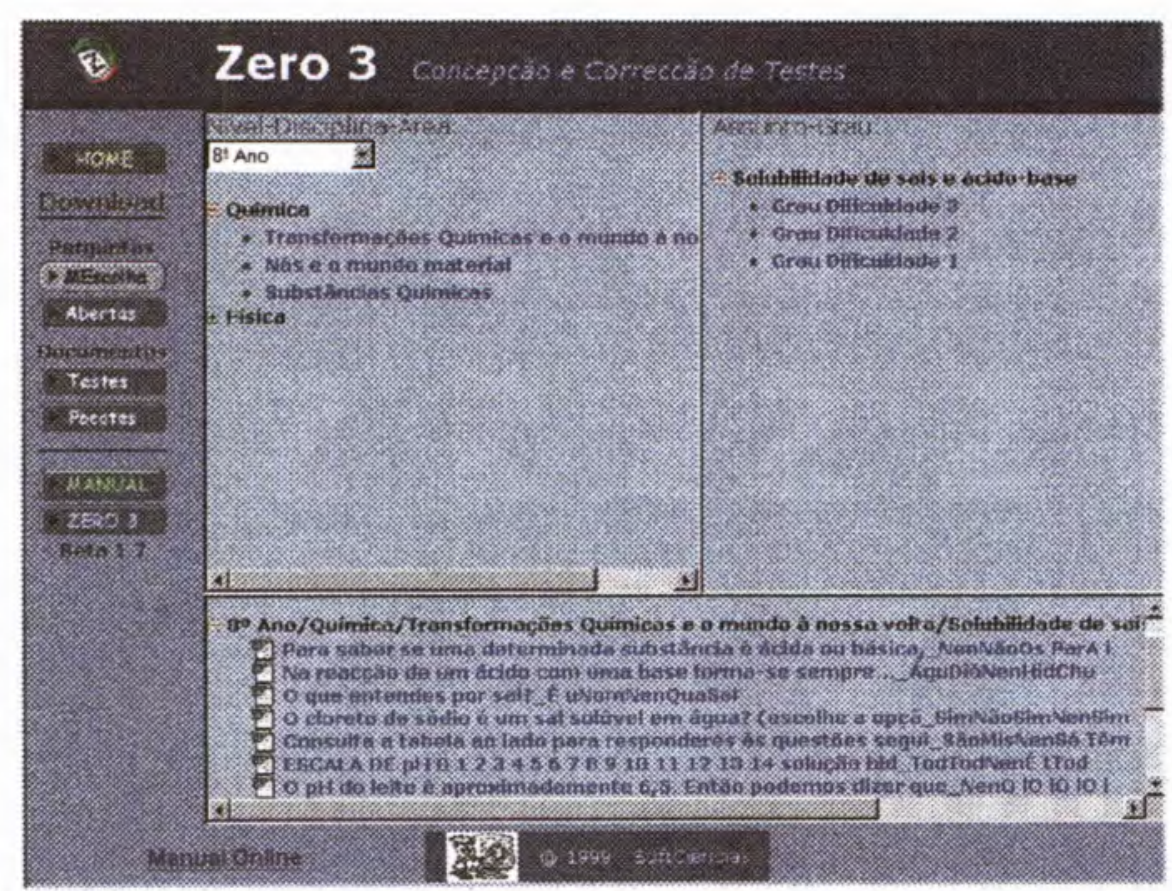

Fig. 4 - Perguntas para o programa Zero, disponiveis na Internet. 
copiado livremente a partir do CDROM. Para gerar testes tem de se abrir a aplicação "Microsoft Word" depois de instalar o programa no disco rígido. A compatibilidade com o programa "Microsoft Word 6.0" representa uma grande vantagem mas tem alguns custos, tornando o programa "pesado". Por este motivo, está em preparação uma versão exclusivamente on line do programa "Zero". Na Internet, já estão disponíveis algumas questões para o $8^{\circ} \mathrm{e}$ do $12^{\circ}$ ano (http: //nautilus. fis.uc.pt/ $\sim$ cec/zero3). Os autores do programa são Carlos Paredes, Ilídio Martins e João Paiva.

Testa FQ 8-9, FQ 10-11, Q 12 e F12

O programa "Testa FQ 8-9" é um conjunto de 780 perguntas de escolha múltipla em Ciências FísicoQuímicas ( $8^{\circ}$ e $9^{\circ}$ anos), elaborado com vista a ajudar professores e alunos nas tarefas de avaliação. As perguntas estão baseadas nos currícula nacionais. Este programa tem particular interesse para os utilizadores do programa "Zero", o programa de concepção e correcção óptica de testes de múltipla escolha atrás mencionado, mas pode ser usado independente dele (por exemplo, fotocopiado). Os autores do "Testa FQ 8-9" são João Paiva e Desidério Pires. Há, além deste, outros "Testas": "Testa FQ 10-11", de Desidério Pires e João Paiva, Testa "Q 12", de Carmo Andrade, João Paiva e Victor Gil e "Testa F12", de Graça Ventura e Carlos Fiolhais. No título, as letras F ou $\mathrm{Q}$ designam Física ou Química e o número designa os anos de escolaridade.

Resumindo, os programas produzidos pela Acção "Softciências" pretenderam, no espírito do título "Softciências", tornar as ciências "duras" mais "moles", mais fáceis de aprender, mas sem fazer concessões nem no rigor do ensino nem no esforço inerente a qualquer aprendizagem. Os vários autores, em geral professores do ensino superior e dos ensinos básico e secundário, têm-se dedicado desde há bastantes anos à introdução de recursos computacionais no ensino, pelo que a preocupação pela conjugação dos aspectos técnico-informáticos com os aspectos pedagógico-científicos foi uma constante. Valorizou-se a interdisciplinaridade, para que a ciência não seja vista pelos alunos como um amontoado de disciplinas estanques. Assim, os nossos programas têm uma dimensão pedagógica alargada, dirigida ao incremento do gosto pelas ciências.

\section{TABELA PERIÓDICA MULTIMÉDIA}

A “Tabela Periódica Multimédia" é uma versão muito aumentada, repleta de imagens (fotos, desenhos, videos, animações) e sons, da "Tabela Periódica", versão 1.0, que é um dos programas educacionais do "Softciências". A "Tabela Periódica Multimédia" engloba uma colecção enorme e pormenorizada de dados de Química e de Física (ver figura 5): inclui informação biográfica, termodinâmica, cristalográfica, de compos- tos e reaç̧ões químicas, espectroscopia atómica, isótopos nucleares, etc. De particular interesse é a mostra de 600 minerais incluída, feita com base na colecção do Museu de Mineralogia e Geologia da Universidade de Coimbra. A versão 1.0, distribuída em disquete, tem a vantagem de correr em máquinas mais antigas, nomeadamente sem leitor de CD, e de incluir no seu manual roteiros de exploração adequados aos programas em vigor. No entanto, a versão do CD-ROM é obviamente a recomendada. Os autores são Carlos Fiolhais, João Cardoso, João Paiva, Miguel Marques e Victor Gil.

\section{WWW QUI - RECURSOS PARA O ENSINO DA QUÍMICA}

WWW Qui é uma página de recursos para os professores de Química que vão desde bases de dados de figuras a software educativo, passando por resumos em português de algumas dezenas de artigos do "Journal of Chemical Education". Destaque particular tem o assunto "Equilíbrio Químico", que inclui variada in-

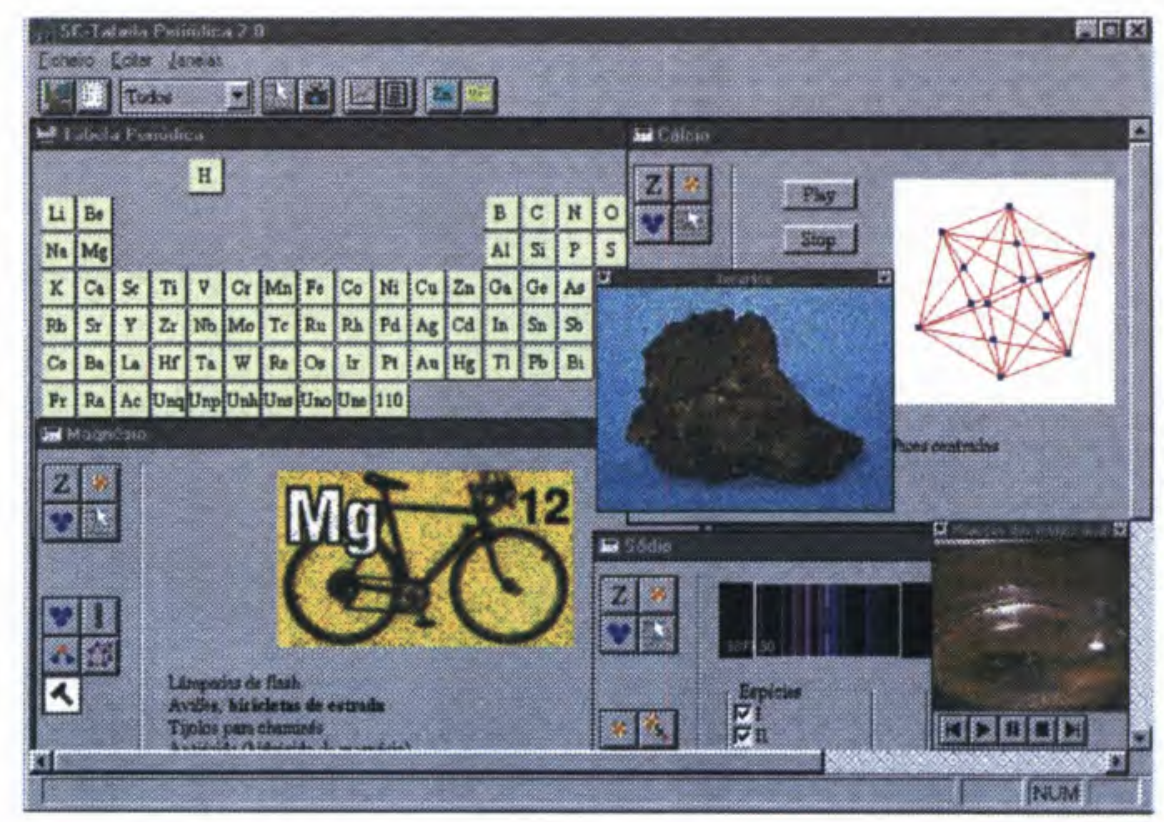

Fig. 5 - O programa "Tabela Periódica Multimédia". 
formação. Os autores são João Paiva, Gustavo Botte e Victor Gil.

\section{Novidades OMNICIÊNCIA na Web}

Está disponível na Internet uma versão on line do CD-ROM (endereço: www.fis.uc.pt/ softc/omni98), onde se encontram algumas actualizações. Também existe aí uma área para sugestões. Das novidades, destaca-se a "WWW Fis" (Recursos para o ensino da Física), semelhante na sua estrutura ao "WWW Qui" e o "Roteiro de Ciência e Tecnologia para jovens" (inventário de recursos para jovens portugueses que se interessam por ciência, por Armando Vieira e Carlos Fiolhais e que vai ser publicado pela editora Ulmeiro). As páginas "WWW Qui" e "WWW Fi" foram apoiadas pelo projecto "Nónio", do Ministério da Educação, num projecto específico submetido pelo Centro de Física Computacional da Universidade de Coimbra.

\section{Impacto do CD-ROM na comunidade escolar e conclusões}

Tem sido muito boa a receptividade dos professores das áreas científicas ao "OMNICIÊNCIA 98" mas, evidentemente, essa recepção está limitada à outra, mais geral, das tecnologias da informação e comunicação nas escolas portuguesas.

As escolas portuguesas com ensino do $8^{\circ}$ ao $12^{\circ}$ anos foram equipadas em 1997 com um computador multimédia e respectiva ligação à rede, num programa do Ministério da Ciência e Tecnologia intitulado "Internet nas Escolas" (http://www.uarte.mct.pt/internetescola). Tratou-se, na nossa opinião, de uma boa e oportuna iniciativa, até porque a rede informática utilizada pelas escolas é a mesma que liga as universidades e unidades de investigação (rede "Ciência, Tecnologia e Sociedade", gerida pela Fundação para a Computação Científica Nacional). O ensino das ciências só pode beneficiar se estiver o mais perto possível das ciências e dos sítios onde elas se produzem. Contudo, e embora o programa "Internet nas Escolas" esteja em expansão, o material que existe nas escolas, por enquanto $\mathrm{e}$ em geral é limitado: só na biblioteca da escola se assegura um computador multimedia e ligado à rede por RDIS e, por outro lado, não são muitos os conteúdos em português (on $\mathrm{e}$ off-line) com interesse pedagógico que alunos e professores podem explorar. O nosso CD-ROM e o "Website" associado constituem um desses raros conjuntos de conteúdos devidamente validados: tem servido de incentivo à utilização do "hardware" existente e de porta de entrada nas tecnologias da informação (não é de mais insistir que informação em "bruto" não significa necessariamente conhecimento organizado!). Há que descobrir novas maneiras de fazer interessar mais os professores pelos notáveis meios que estão ao seu dispor, uma vez que da parte dos alunos existe uma extraordinária receptividade a esses meios e estes cada vez mais se revelam instrumentos de estratégias pedagógicas eficazes [6]. Em Portugal, em nada tem ajudado a descoordenação que existe, de facto, entre o Ministério da Ciência e Tecnologia, que tem a tutela das iniciativas em prol da sociedade da informação, e o Ministério da Educaçāo, uma estrutura burocrática e muito pesada, que tem neste âmbito programas próprios mas geralmente pouco eficazes. Os computadores acabam muitas vezes por ser apenas uma "montra" que pretende fornecer uma imagem de modernidade de escolas que, muitas vezes e em aspectos essenciais, estão antiquadas.

Não podemos afirmar que a utilização dos nossos recursos se faça em larga escala (em larga escala o

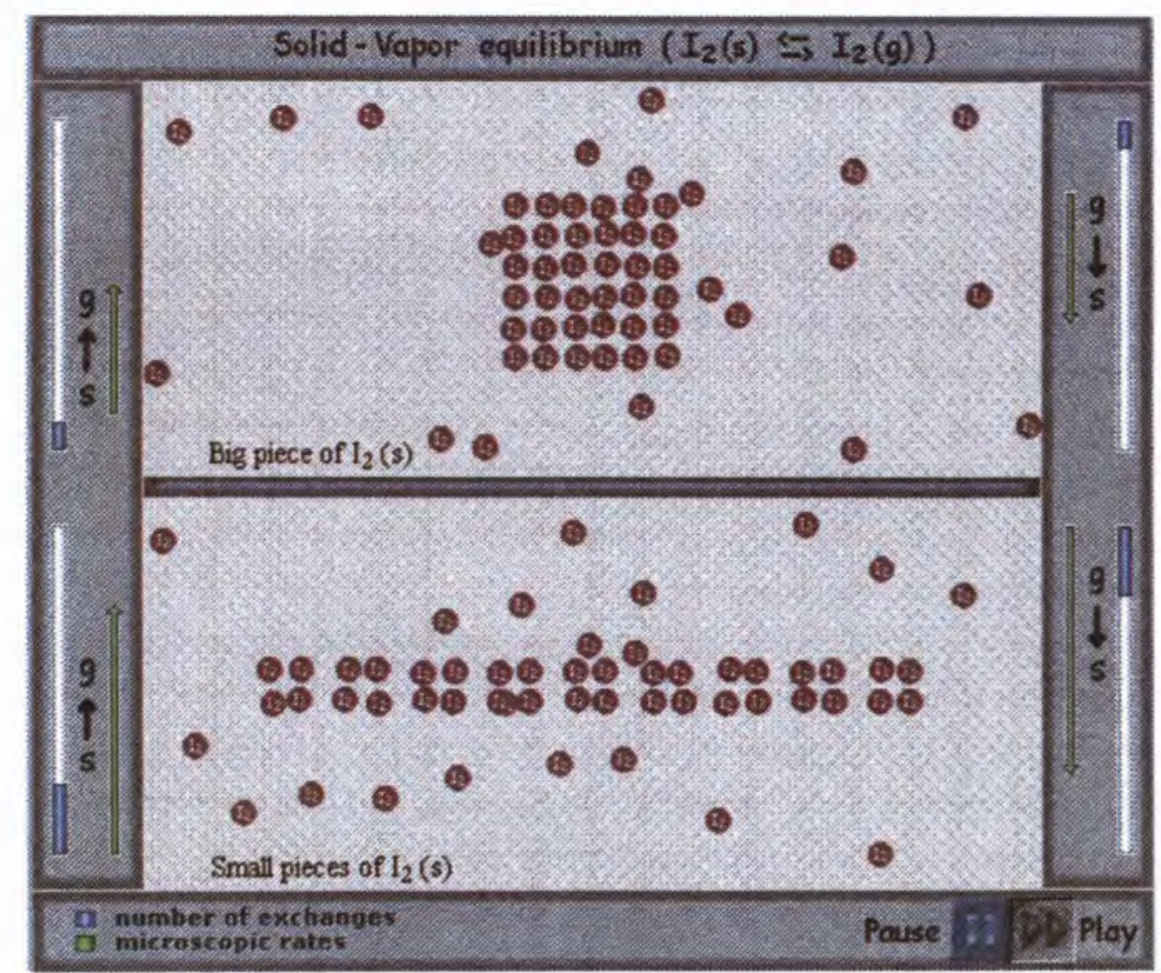

Fig. 6 - Um dos exemplos do «Moleculário : visualização comparativa do equilíbrio sólido-vapor para um pedaço de iodo e para palhetas de iodo. 